\title{
Actuaciones y argumentaciones umbrosas (A propósito de una STS del Pleno de la Sala de lo Contencioso-Administrativo) ${ }^{*}$
}

Juan Igartua Salaverría

DOI: https://doi.org/10.47623/ivap-rvap.108.2017.09

\begin{abstract}
Sumario: Introducción.-I. Descripciones y explicaciones. I.1. La película del caso. I.2. Cambio de escenario: el recurso contencioso. I.3. El obstáculo principal. I.4. El fondo de la demanda recortado. I.5. Análisis del primer motivo... I.6. Y rechazo del motivo. I.7. Segundo motivo de nulidad y contestación. - Il. Observaciones y críticas. II.1. Rotación sin que nadie rote. II.2. "Propuesta» sin propuesta. II.3. Logicismo irrefrenable. Il.4. Escamoteo sistemático.
\end{abstract}

\section{Introducción}

No sé si por nostalgia de una imaginada paz judicial en las alturas del Tribunal Supremo (que a lo peor quizás nunca existió), empiezan a preocupar las cada vez más asiduas resoluciones discutidas en el seno de su Sala 3. ${ }^{a}$ (a juzgar por el adusto ceño del argumentario desplegado en los diversos votos particulares, firmados además - sumando sus respectivos suscribientes - por un elevado número de magistrados). $Y$ con la adicional particularidad -inquietante también - de que tan ostentosos desencuentros intracolegiales suelen congregarse mayormente en torno a asuntos cuya litigiosidad tiene raíz en "acuerdos" (no pocas veces nacidos ellos mismos en medio de viva contestación) provenientes del Consejo General del Poder Judicial (CGPJ).

Precisamente, este par de circunstancias concurren en el asunto del que pasaré a ocuparme. Se trata, en efecto, de un Acuerdo plenario del CGPJ (con 14 votos a favor y 7 en contra), posteriormente impugnado ante elTS y cuya Sentencia (desestimatoria) contó con cuatro votos parti-

* STS de 12 de diciembre de 2016, Sala 3. ${ }^{a}$ en Pleno rec. n. ${ }^{\circ}$ 188/2015. Ponente CUDERO.

(1) Dos favorables a la estimación del recurso (suscritos por 11 Magistrados en total) y dos contrarios incluso a la admisión misma del recurso (que suman las firmas de 3 Magistrados). 
culares - de signo opuesto entre sí, dos a dos(1) - y que, en conjunto, concitaron el apoyo de 14 disidentes frente a los 17 partidarios de lo resuelto.

Como es casi imposible no quedar atrapado entre tanto viento cruzado, no sobrará poner las cartas boca arriba expresando anticipadamente cuál ha sido -en mi personal apreciación (que nada cuenta pero sitúa este comentario) - el punto de vista más convincente; a saber: el de las Vocales perdedoras, en primer término; luego, el de los Magistrados que abogaron por reconocer la razón de la demanda. De todos modos, no voy a recrearme en una innecesaria (y hasta contraproducente) glosa de sus argumentos, meridianos ya de por sí; intentaré más bien, en una tarea de magnitud menor, resaltar algunas argucias muy visibles (bajo la forma de parcialidades) que he creído advertir en la motivación de la Sentencia ( $y$, de paso, también alguna que otra en la actuación del Presidente del Consejo). Aviso que las cursivas correrán de mi cuenta (hasta el final del trabajo y sin excepciones).

\section{Descripciones y explicaciones}

\section{I.1. La película del caso}

A pesar del apelmazado stylus curiae de esta STS, su FD $1 .^{\circ}$ permite destilar cómodamente - en secuencia concisa (2) - la historia (accidentada, como se verá) que tocaba afrontar esta vez a la Sala 3. .

1. Era diciembre de 2014 y a punto de expirar estaba el mandato (anual) de la Comisión Permanente nombrada un año antes, la cual arrastraba ya una baja por la renuncia de la Vocal doña Delia (3).

2. Situación que animó a otras dos Vocales a postularse para ocupar la vacante. Una, doña Estrella, presentó su candidatura el día 11 para la cobertura temporal de la plaza («sin perjuicio de lo que proceda en la renovación anual pendiente»). La otra, doña Socorro, ya al corriente de la oferta de su colega, remitió el día 12 un escrito al Presidente con un propósito similar («presentar su candidatura a dicha plaza»).

(2) Los números que aquí usaré para acotar los pasos que van sucediéndose en el despliegue de esa historia no se corresponden con la numeración que, a los mismos efectos, utiliza la STS (aunque respetan idéntico orden).

(3) Al igual que se acostumbra en los títulos de crédito colocados al término de las películas, no sobraría indicar (entre paréntesis) a qué actrices y actores reales corresponden los distintos nombres que protagonizan los episodios de este relato jurisdiccional en su edición del BOE. Pero no lo haré. 
3. En esta misma fecha (pero datado el día anterior) entró en el Registro del Consejo un escrito de seis Vocales (a saber: doña Mari Jose, doña Delfina, don Everardo, doña Milagros, doña Adoración y la antes mencionada doña Estrella) solicitando del Presidente la inclusión (en el orden del día del Pleno a celebrar el día 18 de ese mes) del siguiente asunto para su debate: «designación de los vocales componentes de las diferentes comisiones", y rogando a la Presidencia que "se tomen las medidas oportunas para que las candidaturas de los/las interesados/as sean presentadas con antelación a la celebración del Pleno». Solicitud que ampliarían los mencionados seis vocales mediante escrito fechado ese mismo día: a) interesando expresamente el cumplimiento del art. 601 LOPJ («el Pleno del CGPJ elegirá anualmente a los Vocales integrantes de la Comisión Permanente») con la inclusión de dicho punto en el orden del día del próximo Pleno; b) señalando que la obligada renovación anual de tal Comisión ha de atenerse a lo dispuesto en el apartado segundo del propio artículo (procurando la rotación de los vocales en la composición anual de la Comisión, lo que parece hacer "deseable» que "todos los vocales fuéramos pasando en algún momento por ella»); c) manifestando, también, que «la elección anual debe realizarse interpretando la norma de forma que tienda al cumplimiento del objeto expresamente establecido por el legislador, es decir, la rotación anual del resto de los vocales, lo que, por una regla aritmética elemental, exige que anualmente se vayan haciendo renovaciones en la composición de la Comisión"; d) solicitando finalmente que "el sistema de votación sea el mayoritario (votación abierta de tres candidatos, siendo elegidos los cinco más votados, cumpliendo las cuotas legales) con el fin de respetar el pluralismo previsto en el art. 1 CE y, en concreto, la representación proporcional de la minoría en la Comisión Permanente».

4. El 15 de diciembre, la Vocal doña Mari Jose (integrante en ese momento de la Comisión Disciplinaria) presenta su candidatura para ocupar en la Comisión Permanente una plaza correspondiente al turno judicial; indicando que, si fuera nombrada para ésta, renunciaría (por incompatibilidad legal) a su puesto en aquella primera.

5. El mismo 15 de diciembre se entrega a los Vocales el orden del día del Pleno a celebrar el día 18, en cuyo punto 1.4 figura la «Propuesta del Presidente del TS y del CGPJ sobre la composición de las comisiones del CGPJ para el año 2015»; anunciándose la designación de vocales para esas comisiones (pero sin incluir nombres) y adjuntándose los escritos ya referidos (el de los seis vocales y los individuales de las tres candidatas). 
6. En idéntica fecha, 15 de diciembre, el Vocal don José Manuel envía un mensaje, a través del correo electrónico, dirigido a los Vocales, al Presidente y al Secretario General del CGPJ, en el que alaba las tres candidaturas presentadas, interesa la renovación anual y la rotación de la Comisión Permanente y propone la elaboración de un calendario para el resto del mandato (a fin de que quienes viven fuera de Madrid puedan organizarse debidamente).

7. En el Pleno del 18 de diciembre - «por asentimiento de los presentes y a propuesta del Presidente» - se retira, para su inclusión en un próximo Pleno, la propuesta del Presidente sobre la composición de las Comisiones, acordando - según consta en acta - "posponer la designación de los integrantes de las Comisiones para el año 2015 a un próximo Pleno, todo ello en aras de procurar el mayor acuerdo posible al respecto".

8. El 21 de enero de 2015, los seis Vocales que habían presentado sendos escritos los días 12 y 13 del mes precedente, y al amparo de los arts. 600 y 599 de la LOPJ, dirigen al Presidente una solicitud de inclusión, en el orden del día del Pleno anunciado para el día 29, del punto siguiente:»Designación de los vocales componentes de las diferentes Comisiones" y piden que la Presidencia adopte las medidas adecuadas para que las candidaturas se presenten con antelación a la reunión del Pleno.Y mediante nota interior enviada a la Secretaría General, la Vocal Mari Jose remite las propuestas elevadas al Pleno para su inclusión en el orden del día, debate y votación.

9. El orden del día del Pleno del día 29, y que fue entregado a los Vocales el 23, incorporaba (en su ordinal IV) una propuesta del Presidente bajo el rótulo de "propuesta de composición de las Comisiones del Consejo para el año 2015». Y en ella se hacía constar, resumidamente lo siguiente: a) los antecedentes (composición de Comisiones anteriores) y preceptos legales aplicables; b)un Anexo I en el que figuraba el escrito de los seis Vocales de 12 de diciembre ya mencionado; c) la relación de Vocales, de uno y otro turno, que podían ser nombrados (excluidos los miembros de la Comisión Disciplinaria); d)la competencia del Pleno para resolver la composición de las Comisiones y las mayorías requeridas para ello, recordando el voto de calidad del Presidente; e) un Anexo II que recogía los escritos de doña Estrella, doña Socorro y doña Mari Jose postulándose para integrar la Comisión Permanente.

10. En el momento de iniciarse el Pleno, el Presidente entregó un escrito ("propuesta de composición de las Comisiones del CGPJ para el año 2015») "sustancialmente idéntico" - dice la STS - al que figuraba en el 
orden del día como punto IV, pero esta vez concretando los nombres de quienes integrarían las distintas Comisiones; y, en lo que respecta a la Comisión Permanente, manteniendo los cuatro miembros ya existentes a los que sumaba el nombre de doña Socorro.

11. Cuando comienza a debatirse el mencionado punto IV, el Presidente se dirige a los vocales en estos términos: a)recuerda los preceptos aplicables y señala que, si bien de los mismos se sigue que el Legislador tuvo la intención de que la Permanente "pueda y deba rotarse», la ley no dice cómo debe hacerse la rotación; b) manifiesta que, ante la alternativa entre rotación total o parcial, él entiende menos disfuncional la parcial; c) señala que el Ministro de Justicia le ha comunicado que llevará un proyecto, al Consejo de Ministros del 6 de febrero, para ampliar hasta siete los miembros de la Permanente; d) propone "para ahora mismo" la incorporación de doña Socorro a la Permanente; "en torno al verano" un jurista y un juez se incorporarían a la citada Comisión; "para fin de año" habría dos nuevas incorporaciones con salida de dos de los miembros designados inicialmente; e) y termina afirmando que la salida de todos los miembros de la Permanente no sería racional ni efectiva.

12. Consta en el acta de la sesión que se genera un debate en torno a esa propuesta en el que los vocales intervinientes expresan críticas (unos) y apoyos (otros). Muy resumidamente: varios vocales censuran el inmovilismo de la propuesta por no respetar el art. 601 LOPJ; califican como mera sustitución y no renovación la incorporación de una sola vocal(4); señalan que las candidaturas presentadas deben debatirse en el Pleno y debe respetarse la pluralidad en la composición de los órganos del Consejo; censuran la absoluta ausencia de consenso tras la suspensión del Pleno anterior; defienden la necesidad de que haya una renovación anual de la Comisión; proponen que, antes de pasar a votar la propuesta del Presidente, se realice un debate sobre la forma de llevar a cabo la votación a tenor de los escritos que un grupo de vocales presentaron formalmente en la Secretaría General; solicitan que se vote separadamente cada una de las Comisiones y uno a uno sus integrantes correspondientes; afirman que con la propuesta del Presidente se deja sin efecto legal el ROF del Consejo cuando dispone que bastan cinco vocales para solicitar la inclusión de un punto en el orden del día. Por su lado, otros vocales manifiestan, al contrario, que la incorporación de una vocal a la Permanente supone una rotación y no una simple sustitución; que la propuesta debe calificarse como verdadera renovación; que lo que se delibera y vota lla

(4) Recuérdese que doña Socorro ocupa la plaza que, tiempo atrás, dejó vacante doña Delia al renunciar a su condición de vocal en el CGPJ. 
propuesta del Presidente) responde a un procedimiento plenamente democrático; que la discusión es irrelevante pues se debaten los tiempos y no la idoneidad de los candidatos.

13. Finalmente, se somete a votación la propuesta del Presidente obteniendo el respaldo mayoritario del Pleno (14 votos positivos frente a 7 negativos). Contra tal decisión se formulan dos votos particulares. En uno (suscrito por los seis vocales aludidos más arriba) se sostiene que la forma en la que se adoptó el acuerdo vulnera el derecho de participación de los vocales y la obligación de someter a la consideración del Pleno una propuesta legalmente realizada que debió ser debatida y votada para obtener la concreción de la voluntad colegiada, pues: a) no es admisible someter a votación unas candidaturas concretas y determinadas no incluidas en la propuesta escrita sometida al Pleno, y b) no puede negarse la posibilidad de que el Pleno se pronuncie sobre una propuesta formulada en tiempo y forma (vulnerándose así el art. 43 ROF del Consejo). En el otro (formulado por don José Manuel) se afirma que se han vulnerado los preceptos legales que obligan a elegir anualmente a los integrantes de las comisiones procurando la rotación y que, al no existir regulación acerca de cómo formular las candidaturas a esos puestos, se ha estado a lo que el Presidente ha decidido en cada Pleno (en este caso, no permitiendo el debate sobre un concreto sistema de votación y proponiendo «in voce» a los integrantes de las comisiones sin que, por tanto, haya habido elección sino mera ratificación de un dictado presidencial bendecido por una amplia mayoría).

\section{I.2. Cambio de escenario: el recurso contencioso}

1. Cuatro vocales del grupo de los seis (en concreto: doña Mari Jose, doña Delfina, doña Milagros y doña Adoración) presentaron ante la Sala 3. ${ }^{a}$, el 27 de marzo de 2015, un recurso contencioso-administrativo contra «el acuerdo número 4 de los adoptados por el Pleno del 29 de enero de 2015».

2. El 7 de abril del mismo año, las recurrentes elevan un nuevo escrito, completando y subsanando el anterior, en el que incluyen como decisiones recurridas "los acuerdos del Presidente del CGPJ adoptados en el Pleno del 29 de enero pasado, que impidieron el ejercicio por las vocales del derecho a elegir y ser elegidas para las comisiones del Consejo, al haber denegado el Presidente la petición de que se sometiera a votación las propuestas realizadas por seis vocales, así como las candi- 
daturas presentadas por varias vocales y que, finalmente determinaron el contenido del acuerdo aprobado por el Pleno igualmente objeto de recurso".

3. La Sección Primera de la Sala 3. ${ }^{a}$, en un Auto de 16 de julio de 2015, inadmitió el recurso, al considerarlo extemporáneo, en lo que afectaba a los acuerdos del Presidente del Consejo (mencionados en el escrito de 7 de abril), pero lo admitió en lo concerniente a la decisión del Pleno (de 29 de enero de 2015) sobre el punto cuatro del orden del día.

4. En el escrito de demanda se habían aducido tres motivos de impugnación contra el acuerdo que finalmente constituye el objeto del recurso.

En el primero (al amparo del art. 62.1 de la Ley 30/1992), se reputa nulo tal acuerdo por entenderse que el mismo ha sido dictado con infracción de las reglas esenciales para la formación de la voluntad del órgano colegiado (contenidas en los arts. 598 y 600 LOPJ y en los arts. 18, 25, 37, 42,43 y 45 del ROF del CGPJ).

En el segundo (apoyado en el art. 23.2 CE, en relación con los arts. 600.2 y 601.1 LOPJ), se propugna su nulidad igualmente al haberse soslayado, por obra del Presidente y asumida luego por el Pleno, el derecho de seis vocales a que su propuesta de renovación de la Comisión fuera debatida y sometida a votación y a no haberse efectuado una verdadera elección de la Comisión.

En el tercero (formulado con carácter subsidiario de los dos anteriores), se sostiene que la nulidad derivaría de la vulneración del art. 601.2 LOPJ por no haberse procedido a renovar la Comisión, impidiendo la efectiva participación de los vocales y la pluralidad del órgano de gobierno.

Y en el apartado de conclusiones, se aclara o concreta aquella pretensión interesando la nulidad del acuerdo impugnado y el reconocimiento de sus derechos a que la propuesta que presentaron fuera debatida y votada en el Pleno y a participar - ejerciendo el sufragio tanto activo como pasivo- en la renovación de las Comisiones del CGPJ a través de la correspondiente elección.

\section{I.3. El obstáculo principal}

En su FD $3 .^{\circ}$, la Sala describe las alegaciones de la Abogacía del Estado contra la admisibilidad del recurso, las cuales comparten en última instancia un mismo problema como denominador común; éste: si las vocales recurrentes ostentan o no un interés legítimo que pueda ser tutelado en sede judicial a través de ese recurso. $Y$ es importante señalar al 
respecto que el interés de la parte actora (según subrayan las propias demandantes) no se ciñe a una mera discrepancia jurídica sobre el acuerdo recurrido sino a que éste comporta una supuesta violación de su estatuto como vocales del CGPJ, de su ius in officium, es decir del conjunto de facultades que identifican sus funciones $y$ atribuciones como integrantes de ese órgano constitucional.

El escollo fundamental con que tropieza tal pretensión para ser acogida favorablemente radica en la letra del art. 20.a) LJCA: «No pueden interponer recurso contencioso-administrativo contra la actividad de una Administración Pública» "los miembros de sus órganos colegiados, salvo que una Ley lo autorice expresamente».

Frente a ello, la Sala extrae varias consecuencias relevantes para la solución del caso (FD 7. ${ }^{\circ}$. La primera, que el art. 20.a) puede no entrar en juego cuando medie un interés legítimo digno de protección ex art. 19.1 a) de nuestra ley procesal. La segunda, que tal interés legítimo no tiene por qué ser forzosamente personal o privado, sino que puede vincularse también al ejercicio de las funciones institucionales que resultan esenciales para el desempeño de la actividad como miembro de un órgano colegiado. La tercera, que cabe defender en sede jurisdiccional la disconformidad frente a una actuación del órgano colegiado cuando se razone y constate debidamente (prima facie, no obstante lo que pueda resultar en cuanto al fondo) que tal actuación ha vulnerado, desconocido o limitado ilegítimamente las facultades o derechos que constituyen el núcleo esencial en el ejercicio de la función de quienes conforman el órgano colegiado.

Todo ello, en el bien entendido de que la invocación de un interés legítimo de esa naturaleza no podrá ser manejada por la parte recurrente como un artificio o una alegación instrumental para conseguir lo que la ley no permite. Y, en paralelo, también el órgano judicial competente deberá excluir de su cognición aquellos aspectos que, no afectando al ejercicio de la función institucional, se refieran en puridad a pretensiones de mera legalidad o de oportunidad (que sólo tienen encaje en el seno del órgano colegiado mismo).

Pagada la cuota de los distingos, la Sala no encuentra ya ningún motivo para diferir la conclusión (FD $8 .^{\circ}$ ) de que el interés invocado por las recurrentes ha de reputarse efectivamente legítimo, pues es evidente que se inscriben en el conjunto de facultades y competencias relativas a su función aquéllas que se estiman conculcadas, como son: las de proponer asuntos para su debate en el Pleno, o que estos asuntos se incluyan en el orden del día correspondiente, o que se discutan y voten debidamente las propuestas formuladas, o que puedan participar - según los términos de la normativa aplicable- en la composición de las distintas Comisiones del Consejo. 


\section{I.4. El fondo de la demanda recortado}

Tras un puntilloso desmenuzamiento (FD 9. ${ }^{\circ}$ ) y posterior rechazo (FD $10^{\circ}$ ) de las objeciones alegadas por el Abogado del Estado oponiéndose a la admisión del recurso y que aquí soslayaré, la Sala afronta ya los tres motivos de nulidad contra el acuerdo del Pleno que se aducen en la demanda (FD 11). Y que son: a) la ausencia total y absoluta de procedimiento y el desconocimiento de las reglas esenciales para la formación de la voluntad del órgano colegiado; b) la lesión de derechos susceptibles de amparo constitucional; y c) la vulneración del art. 601.1 de la LOPJ en conexión con el art. $1 \mathrm{CE}$.

Pero en su desmontaje pieza a pieza de esa triada de motivos, "la Sala entiende que no todos esos motivos de nulidad están conectados con el interés legítimo que ha permitido a las cuatro vocales del CGPJ impugnar en vía judicial un acuerdo del Pleno». A su juicio, el tercero de ellos contiene una mera "pretensión de legalidad» "desconectada del interés legítimo", aquél que - como ya se dijo- permitiría a las demandantes eludir el régimen de clausura impuesto con carácter general por el art. 20.a) LJCA y buscar tutela extramuros, en los tribunales.

$Y$ no parece que las mismas demandantes hubieran depositado mucha fe en la eficacia dialéctica de esa tercera alegación, pues - destaca la Sala - el susodicho motivo de impugnación se presentó con "carácter subsidiario", con un "escaso desarrollo argumental» que Ilama la atención, sin ofrecer «ni una sola vinculación entre el repetido ius in officium y la decisión material del Pleno de fijar la composición de la Comisión Permanente incluyendo a unos $u$ otros vocales en los términos acordados por la mayoría», y sin siquiera esforzarse "en constatar que una interpretación distinta de la adoptada por el Pleno(...) era la única que respetaría en su integridad el adecuado ejercicio de las funciones esenciales que la ley les atribuye como vocales".

En cualquier caso - recapitula el TS - «consideramos que la pretensión de nulidad del acuerdo por contravenir lo dispuesto en el art. 601 LOPJ, o por vulnerar la pluralidad en la composición de la Permanente que postula la Exposición de Motivos o por desconocer el pluralismo político como valor superior de nuestro ordenamiento constituye, en puridad, una impugnación amparada en la defensa de la legalidad de la actuación administrativa en la que se muestra una discrepancia con la interpretación que la mayoría del Pleno ha efectuado de los preceptos aplicables, discrepancia que solo tiene su adecuado encaje y que únicamente puede ser ejercitada por los miembros del órgano colegiado en el seno de éste". Además, "partiendo del hecho no controvertido de que no existe en la normativa vigente un derecho de los vocales a formar parte de una u otra Comisión del CGPJ, o a hacerlo en un determinado mo- 
mento, o durante un concreto plazo, no alcanza la Sala a entender en qué medida una decisión mayoritaria del órgano competente sobre el alcance y significación de aquellas expresiones contenidas en el art. 601 puede afectar al ius in officium de los vocales que han discrepado"; debiendo añadirse a ello que «tampoco puede afirmarse en absoluto que el tenor de aquel precepto permita identificar un derecho de los vocales, integrado en el núcleo esencial del repetido ius in officium, a que las Comisiones se renueven en la forma defendida por las recurrentes o que la rotación de los distintos vocales se efectúe en los términos que ellas proponen». De manera que "la defensa de una interpretación distinta sobre la renovación o sobre la rotación a las que se refiere el citado precepto solo puede hacerse en el seno del órgano colegiado al que (aquéllas) pertenecen".

Así las cosas, el análisis del fondo del asunto deberá reducirse a los dos primeros motivos de impugnación aducidos en la demanda, pues en ellos sí cabe distinguir - asegura la Sala - una clara conexión con el interés legítimo que habilita a las demandantes para comparecer ante el Tribunal.

\section{I.5. Análisis del primer motivo...}

EI FD 12 de la sentencia se destina por entero a la disección del primero de los motivos en el que se enumeran las - a juicio de la actora«irregularidades habidas en el iter procedimental de las que se derivó la ilegal formación de la voluntad del Pleno" en lo relativo a "quórum, convocatoria que incluye el orden del día, composición y votación", y que se infieren examinando las reglas dispuestas en los preceptos siguientes: a) El art. 600.1 LOPJ, que obliga a celebrar sesión extraordinaria del Pleno cuando lo consideren oportuno cinco vocales. b) Los arts. 36 y 37 ROF del CGPJ que se refieren a la necesidad de que la convocatoria de las sesiones plenarias exprese el orden del día y sea comunicada a los consejeros al menos con antelación de tres días, así como la obligación de repartir a los vocales la documentación - con los antecedentes necesarios y, en su caso, con la propuesta correspondiente - referida a cada punto del orden del día. c) Los arts. 598 LOPJ y 25 ROF del Consejo que establecen las competencias de la Presidencia para fijar el orden del día y para proponer las cuestiones que estime oportunas. d) El art. 18 ROF, cuyo apartado quinto reconoce el derecho de los vocales a formular propuestas escritas y a su inclusión en el orden del día de las reuniones del Consejo. e) El art. 42 ROF en el que literalmente se dispone que "la deliberación y examen de los asuntos del orden del día se realizará bajo la dirección y ordenación del Presidente», con el añadido de que «intervendrá en primer lu- 
gar el proponente de cada uno o el representante de la Comisión proponente y a continuación se procederá al debate de la propuesta». f) Y el art. 45 ROF, a cuyo tenor «no podrán adoptarse acuerdos sobre temas o materias no incluidos en el orden del día, o carentes de propuesta escrita, salvo que, hallándose presentes todos los miembros del Consejo se decida lo contrario por unanimidad".

Pues bien, la actora - dice la Sala - : a) Señala que la solicitud e inclusión en el orden del día (del punto atinente a la "designación de los vocales componentes de las diferentes comisiones") no fue atendida, vulnerándose así su derecho reconocido por el art. 18.5 ROF. b) Afirma, además, que el Presidente, incumpliendo el mandato de los arts. 598 LOPJ y 25 ROF, en lugar de incorporar al orden del día la propuesta formulada por los seis vocales «no incluyó el asunto en los términos propuestos por los vocales, limitándolo a los términos escritos de su propuesta que no incluía el cambio de personas que debía implicar». c) Sostiene, también, que se vulneró el art. 37 ROF, pues la propuesta del Presidente no estaba documentada y era claramente incompleta porque no recogía los nombres de los vocales que integrarían las Comisiones, cosa que solo hizo (in voce) en el Pleno mismo, sin tiempo bastante para el estudio, análisis, debate y votación de la propuesta y sin que los miembros del Pleno salvaran ese defecto mediante decisión unánime. d) Asevera, finalmente, que "la decisión unilateral y contraria a derecho del Presidente impidió a los (sic) vocales, doña Mari Jose y doña Estrella, a (sic) mantener, defender y hacer efectiva la candidatura presentada para formar parte de la Comisión Permanente».

\section{I.6. $Y$ rechazo del motivo}

Apartado autónomo merece el pormenorizado razonamiento que la Sala opone a la pretensión que alberga el primero de los motivos.

1. En primer lugar, no cabe afirmar que, en la adopción del acuerdo cuarto, se prescindiera de las reglas esenciales para la formación de la voluntad del órgano colegiado; por cuanto: a) se votó una propuesta ( «composición de las comisiones del CGPJ para el año 2015») incluida en el orden del día y entregada en plazo a los vocales; b) la decisión fue adoptada por el Pleno (órgano competente), en sesión con presencia de todos sus miembros (quórum adecuado) y con el respaldo de la mayoría requerida.

2. Verdad es que la propuesta del Presidente debatida en el Consejo no contenía los nombres de los vocales que habrían de integrar las distintas 
Comisiones y cierto también que tales nombres no fueron comunicados hasta el inicio del debate. Con ello, sin embargo, no se contravenía -al punto de hacer nulo el acuerdo- lo dispuesto en los artículos del ROF aludidos en la demanda; toda vez que: a) el art. 45 ROF solo prohíbe que en el Pleno se debata sobre temas o materias no incluidos en el orden del día o carentes de propuesta escrita; lo cual no puede interpretarse con una rigidez tal que «impida completar, mejorar o alterar aquellos particulares de la propuesta en los términos que puedan resultar del debate»; b) "la propuesta fue efectivamente documentada y entregada», con la salvedad de que no incluía a las personas concretas que integrarían las distintas Comisiones; extremo que no puede tener carácter invalidante si el Pleno debatió y votó sobre la forma de integrar las Comisiones y sobre quiénes debían ser sus componentes; c) del expediente y de las manifestaciones de la actora se desprende que ninguno de los vocales planteó la insuficiencia de la propuesta por no contener el nombre de los miembros, ni adujo su falta de documentación por aquella omisión, ni la contravención de los preceptos del ROF por la incompleta propuesta que había formulado el Presidente; d) las intervenciones contrarias a la adopción del acuerdo se limitaron a denunciar la falta de debate sobre la propuesta efectuada por el "grupo minoritario", o a criticar que aquello no constituía una verdadera renovación de la Permanente, o a discrepar de la decisión del Presidente de no incluir en el orden del día la propuesta de los seis vocales, o en fin a defender lo que se derivaba del respeto al pluralismo.

3. Ni siquiera puede admitirse que la propuesta efectuada por los seis vocales "no fuera objeto de debate». Del expediente se sigue que el punto del orden del día contaba con unos Anexos en los que figuraban tanto la propuesta de seis vocales como la disposición de las Sras. Mari Jose, Socorro y Estrella para entrar en la Permanente; y ello evidencia que todos los vocales conocían con la debida antelación tanto lo uno como lo otro. Del acta de la sesión se desprende igualmente que los vocales del Consejo "debatieron sobre aquella propuesta" y acerca de cómo debían renovarse las Comisiones (comprendido el sistema postulado por los seis vocales).

4. Los defectos formales (que harían nulo el acuerdo recurrido, según los demandantes) son imputables en su práctica totalidad al Presidente del CGPJ (no incluir en el orden del día el escrito de los seis vocales y las candidaturas de tres de ellos). Sin embargo, tales actuaciones han quedado fuera del objeto del proceso (pues así lo determinó el auto de la Sección Primera), de manera que la infracción de los arts. 598 y 600 LOPJ y de los arts. 25, 36 y 37 ROF, atribuible al Presidente, no invalidarían el acuerdo del 
Pleno que ha respetado las reglas esenciales de la formación de la voluntad (quórum, convocatoria, composición, deliberación y votación).

$\mathrm{Ni}$ aún si la actuación del Presidente fuera "comunicable» (contaminara) a la decisión del Pleno cabría anular la decisión recurrida. Pues aun aceptando a efectos polémicos que hubo irregularidades en la confección del orden del día, sin embargo, pese a la no incorporación formal de lo propuesto por los seis vocales, tales datos fueron suministrados a los componentes del Pleno junto con el orden del día y fueron efectivamente objeto de debate y votación según aflora en el expediente. De éste se desprende, en efecto, que: a) todos los integrantes del Pleno tuvieron puntual conocimiento de la propuesta de los seis vocales y de la tres candidaturas pues figuraban como Anexos al punto cuarto del orden del día; b) en la deliberación previa a la votación, algunos vocales se refirieron concretamente a aquella propuesta, interesando incluso que fuera votada antes que la del Presidente, defendiendo la forma en que debían interpretarse los preceptos concernidos, y criticando al Presidente por actuar contra la normativa aplicable; c) la mayoría del Pleno (14 consejeros) no coincidió con la opinión crítica de aquellos vocales, ni con su pretensión de que las Comisiones (la Permanente, sobre todo) se renovaran según ellos postulaban, ni con la idea de que la propuesta del Presidente era una mera sustitución y no una renovación: votaron, tras las diferentes intervenciones en el debate, a favor de la propuesta del Presidente una vez concretadas las composiciones de las referidas comisiones.

Por tanto, el supuesto defecto formal no ha menoscabado a la resolución recurrida de los requisitos esenciales para alcanzar su fin, ni ha producido indefensión material a los destinatarios un acuerdo respetuoso de las reglas de procedimiento exigibles (competencia, quórum, convocatoria y decisión mayoritaria) y tampoco puede alegar indefensión real y efectiva quien ha visto que sus propuestas han sido conocidas por los integrantes del Pleno y han podido ser debatidas en su seno.

5. Por último, no puede sostenerse con éxito que el acuerdo recurrido haya privado a las Sras. Mari Jose y Estrella de su derecho a mantener, defender y hacer efectiva su candidatura a la Permanente. Por varias razones: a) como antes se señaló, no puede afirmarse que de la normativa vigente se desprenda la existencia de un derecho de los vocales a formar parte de alguna Comisión del Consejo, o a hacerlo en determinado momento o por un plazo concreto; b) doña Estrella, que no consta haya recurrido aquella actuación, no está representada por las hoy demandantes; por lo que éstas no pueden basar su impugnación en defensa de un concreto interés de persona distinta; c) doña Mari Jose (al margen de si su candidatura era viable por cuanto ya pertenecía a la Comisión Disciplinaria) tomó la palabra en el debate previo al acuerdo recurrido solicitando 
que antes de la votación se hiciera un debate sobre la forma de llevarla a cabo a tenor de los expuesto por los seis vocales en sus escritos formalmente presentados en la Secretaría General; pretensión que fue rechazada por la mayoría, la cual decidió votar única y exclusivamente una propuesta, la del Presidente, con cuya aprobación no solo se excluía que las Comisiones tuvieran una composición distinta sino también la aceptación de la candidatura de doña Mari Jose (dado que en la propuesta del Presidente se excluía a los miembros de la Comisión Disciplinaria).

\section{I.7. Segundo motivo de nulidad y contestación}

En el inicio del FD 14, la Sala asegura que con lo recién expuesto se ofrece ya una respuesta a la práctica totalidad de los argumentos que sustentan el segundo motivo de nulidad.

Según las recurrentes, el acuerdo impugnado habría lesionado derechos fundamentales susceptibles de amparo constitucional (los reconocidos en el art.23.2 CE en relación con los arts. 599.1.6, 600.1 y 601.1 LOPJ y los arts. 18, 43 y 45 ROF) «al adoptarse el acuerdo recurrido soslayando la propuesta de seis vocales (...) sobre la renovación de la Comisión Permanente que no pudo ser debatida ni sometida a votación en el Pleno sino que, en su lugar, se aprobó la formulada verbalmente por el Presidente».

La Sala anticipa sin contemplaciones que «difícilmente puede prosperar esta alegación cuando hemos afirmado que el acuerdo recurrido no vulneró aquellos preceptos». No obstante, considera necesario detenerse en unos apartados del motivo de impugnación donde se defienden tres cosas: a) el derecho fundamental mencionado ha sido vulnerado en el proceso de renovación de las Comisiones; b) ante la ausencia de normas específicas sobre el procedimiento para renovar la composición de esas Comisiones, debió efectuarse una elección orientada a la materialización de la rotación anual de la Permanente a fin de que formen parte de ella todos los vocales; c) la negativa a debatir la documentada propuesta de los seis vocales ha vulnerado el procedimiento de forma sustancial impidiendo el ejercicio de un derecho fundamental al imposibilitar que los vocales ejerciten sus facultades conforme a la colegialidad del Consejo y la paridad de sus miembros.

La Sala concede que las recurrentes llevan razón cuando constatan que el ROF actual no contiene regulación suficiente para que la nueva estructura del Consejo se acomode a los principios de la LO 4/2013. Ahora bien - agrega - eso no conduce a concluir que la composición de las Comisiones deba necesariamente realizarse en los términos propuestos por las demandantes (y por los seis vocales en su día). Tampoco se entiende 
- prosigue la Sala - por qué la falta de un concreto iter procedimental haga nula una decisión aprobada por una mayoría del Consejo que ha entendido como conforme a las determinaciones previstas por la LOPJ la propuesta efectuada por el Presidente. Y aún menos - remata el TS cabe inferir que se ha vulnerado el derecho fundamental recogido en el art. 23.2 CE por la sola circunstancia de que no se votara la propuesta de los seis vocales (calificada por las demandantes como la única o la más idónea para garantizar la colegialidad del Consejo y la paridad de sus miembros en la toma de decisiones).

La Sala no estima que resulte afectado o lesionado el derecho al cargo por el hecho de que el Pleno no haya aceptado una determinada forma de proceder para conformar las distintas comisiones; sobre todo si ninguna norma jurídica reconoce a los miembros del Consejo un derecho a formar parte de alguna de las comisiones o de hacerlo en un momento o en otro.

Y en cuanto a la negativa a debatir la documentada propuesta de los seis vocales, la Sala estima que debe insistirse en lo ya dicho con reiteración: que tanto la propuesta de los seis vocales como el interés de tres consejeras para formar parte de la Permanente eran extremos conocidos con antelación por todos los miembros del Pleno e incorporados como Anexos al orden del día, que en el Pleno se debatió cuanto ya se ha descrito repetidas veces y, finalmente, que el Pleno decidió la composición de las Comisiones en los términos especificados por el Presidente al inicio de la sesión.

Lo que en el fondo interesa a las demandantes - cree adivinar la Salaes que se «emita una declaración sobre cuál deba ser la interpretación del artículo 601 LOPJ y sobre qué procedimiento resulta idóneo para dar cumplimiento a ese precepto y al resto de los que se refieren a la composición de las Comisiones"; "y se hace defendiendo que existe un derecho (de los vocales) a que la renovación y la rotación a las que el artículo citado se refiere deba efectuarse de forma distinta a como el Pleno decidió mayoritariamente". Lo cual "constituye en realidad una pretensión de mera legalidad», sin recorrido procesal por tanto a tenor del art. 20. a) LJCA.

\section{Observaciones y críticas}

A la vista ha quedado -o eso creo-, si miramos desde el siempre auspiciado prisma del juego limpio, el accidentado proceder del Presidente del Consejo. Pero a nada conduce, ahora, elaborar el censo de todas las raras incidencias observadas (desde la particular óptica de quien esto suscribe, claro está). Si acaso, se traerá a la memoria el recuerdo de aquéllas cuya salpicadura enturbie el razonamiento de la sentencia. 


\section{II.1. Rotación sin que nadie rote}

Consta en el expediente, y así se refleja en la sentencia, el exordio explicativo del Presidente previo a la lectura de su propuesta. Discurso que, en lugar de ajustarse a la neutra legalidad, parece haber preferido la solícita amabilidad de una componenda doméstica (en la que todos los vocales verían finalmente cumplidas sus expectativas, pero cuando y como quisiera el Presidente).

Sobre el planteamiento del Presidente se proyectan las sombras de dos errores, nada desdeñables. El primero consiste en inventar una duda de interpretación textual allí donde no la hay; el segundo -aun suponiendo que alguna indeterminación existiera - en no resolverla sino en disolverla. Iré por orden.

1. Nadie niega que la regulación legal atinente a la renovación de la Comisión Permanente sea lacunosa. Pero el enclave de esa carencia no está allí donde el Presidente la sitúa sino en otro lugar. En breve: la letra de la ley ofrece una respuesta diáfana y completa a la cuestión de si la rotación de los vocales en la renovación de la Permanente ha de ser total o puede quedarse en parcial. El problema es otro. Veámoslo más despacio.

La rotación implica, por definición, que hay unos vocales que salen (Ilamémosles "rotados") para que otros entren (los "rotantes»). Pues bien, lo que la LOPJ ha dejado sin regular no es cuántos (de los posibles rotados) salen sino quiénes (de los posibles rotantes) entran; asuntos bien distintos e independientes entre sí.

A) Respecto de lo uno, la previsión legal es de una literalidad sin flecos interpretables. En efecto, tras disponerse en el art. 601.1 que «el Pleno del CGPJ elegirá anualmente a los Vocales integrantes de la Comisión Permanente», en el art. 601.2 se especifica que en la composición anual de la Comisión Permanente - exceptuados los Vocales de la Comisión Disciplinaria - "se procurará la rotación anual del resto de los Vocales». ¿Provoca, acaso, alguna perplejidad el significado que ha de atribuirse a la expresión "rotación anual», a la preposición "de», y a la palabra "resto»?

Es sintomático que el Presidente haya eludido empeñarse en una exégesis disyuntiva razonada, si la hubiera, antes de sugerir -abiertamente contra litteram y sin ningún argumento - que la ley deja abierta «la alternativa entre rotación total o parcial».

B) No obstante, llevaría razón el Presidente al señalar que "la ley no dice cómo debe hacerse la rotación", pero si se apuntara al otro aspecto. Es decir, la ley no determina el procedimiento a seguir por el Pleno para 
elegir a quienes sucederán a los vocales salientes; vacío normativo, no obstante, que en nada afecta al alcance (si total o parcial) de la rotación.

Y eso explica que la minoría propusiera en su escrito un método de elección para colmar precisamente lo que "la ley no dice» (en palabras del Presidente), y que no ha de confundirse (como le ocurrió al Presidente) con lo que la ley sí dice.

2. Ya desde el primer paso, el Presidente se ha equivocado, creo. Ello no impide, sin embargo, reconocer que la claridad textual pueda ser un límite franqueable cuando haya motivos suficientes para ello (que habrán de explicitarse y justificarse convenientemente). Nada de eso ha sucedido en esta ocasión.

Es verdad que el Presidente invoca el punto de vista de la funcionalidad, pero lo hace para preferir uno de los dos cuernos del dilema (la rotación parcial por encima de la rotación total), cuando en realidad el problema es otro y anterior: cómo generar un dilema a partir de una regulación literalmente unidireccional. Es lo que el Presidente no ha justificado.

Peor todavía. A la vista de la concreta composición que el Presidente proponía, el razonamiento real subyacente sería éste: si el Legislador no ha determinado una entre las varias maneras posibles de proceder a la rotación, entonces ninguna de ellas es vinculante, de modo que puede prescindirse hasta de la rotación misma, al más puro estilo salomónico. Compruébese, si no, cómo en la propuesta presidencial ninguno de los vocales rotaba, todos repetían. La incorporación de doña Socorro, para cubrir una plaza vacante de tiempo atrás, podrá llamarse cualquier cosa menos "rotación" (que es el término específico que emplea la ley y no el genérico de "renovación» (5), tras el que se escudaba el Presidente). ¿Rotación total o rotación parcial? Ninguna rotación.

\section{II.2. «Propuesta" sin propuesta}

No sólo el Presidente, también la Sala cometió errores de concepto. Los más ostentosos pululan alrededor del significado de "propuesta» (palabra inicial en la formulación del punto cuarto del orden del día: "Propuesta de composición de las Comisiones del CGPJ para el año 2015») y cuya incidencia podría comprometer hasta la misma validez del correspondiente acuerdo adoptado por el Pleno.

(5) No habría óbice para considerar que un órgano se había «renovado" mediante la reelección de sus integrantes, como sucedía esta vez; pero de ningún modo habría "rotación». 
Pues a esos efectos precisamente, como ya se vio, las vocales recurrentes hacían hincapié en al art. 45 ROF que dice: "No podrán adoptarse acuerdos sobre temas o materias no incluidos en el orden del día, o carentes de propuesta escrita, salvo que, hallándose presentes todos los miembros del Consejo, se decida lo contrario por unanimidad». Repárese en que el susodicho art. 45 distingue dos supuestos: uno formal y otro material. Formal: temas o materias no incluidos en el orden del día. Material: carentes de propuesta escrita (es decir, del contenido de lo que se propone). En este caso, a juicio de las demandantes, habría una "propuesta» (formal) sin propuesta (material). ¿Qué resolvió la Sala?

1. Desde los renglones que la Sala destinaba a narrar las vicisitudes del caso que llegaba a sus manos ya se presentía lo que iba a suceder.

Me refiero a aquel pasaje del FD $1 .^{\circ}$ donde se describe que: "Al inicio del Pleno se hace entrega por el Presidente de un escrito - que se adjunta al acta correspondiente - en el que consta una "propuesta de composición de las Comisiones del CGPJ para el año 2015" ". Y, de seguido, la Sala deja caer, como si fuera de soi même, una apreciación (que no una descripción) de cosecha propia, al añadir que: «El escrito es sustancialmente idéntico a la propuesta que se incluyó en el orden del día (...) pero ahora se concretan los nombres de los integrantes de las distintas Comisiones».

Inexplicable un desliz (por ponerle un nombre) tan ostentoso, puesto que existe una diferencia esencial entre ambos escritos. Una "propuesta» se define como propuesta si propone algo. Y, salvo los nombres, el Presidente no proponía nada. En el orden del día, donde no figuran los nombres, se anuncia una propuesta (desconocida, de momento) pero no se enuncia la propuesta; por tanto no hay propuesta. Una situación radicalmente diversa se producirá después cuando en el segundo escrito(6) se consignen los nombres y apellidos de aquellos vocales que el Presidente propone para componer las distintas comisiones. Entonces claro que hay propuesta, pero sólo entonces.

2. Cabría replicar a lo recién apuntado que la información omitida en una escueta redacción del orden del día bien puede ser recabada consultando la documentación complementaria que eventualmente se adjunte. $Y$ hacia esa dirección apunta el razonamiento de la Sala.

Así en el FD $13 .^{\circ}$ de la sentencia se lee que: "La propuesta fue efectivamente documentada y entregada con antelación a los vocales, como exigen los artículos 36 y 37 del ROF, con la salvedad de que no incluía a las personas concretas que integrarían las distintas Comisiones».

(6) Cuyo título, por cierto, es el calco del punto cuarto del orden del día (a saber: «Propuesta de composición de las Comisiones del Consejo General del Poder Judicial para el año 2015»). 
"Salvedad" que nada salva, todo lo contrario. Porque ¿qué otra cosa, sino precisamente eso que "no incluía» la documentación, constituye la "propuesta"? Encima, ninguno de los anexos agregados al orden del día servía para documentar absolutamente nada de la propuesta presidencial: ni el recordatorio de la normativa vigente o la entonces actual composición de las distintas Comisiones, ni el censo de los elegibles, ni las peticiones de los seis vocales, ni las ofertas de las tres candidatas... Todo ello era a lo sumo como un marco (los cuatro listones del bastidor) pero sin cuadro (lienzo pintado). Ninguno de estos documentos reflejaba (ni en todo ni en parte) propuesta alguna del Presidente. Es más, se daba la paradoja de que, mientras había un punto del orden del día (el famoso cuarto) sin documentación, en cambio se adjuntaba una documentación (el escrito de los seis vocales y las propuestas de las tres candidatas) a la que no correspondía ningún punto explicitado en el orden del día. ¡Raro!

Pues no menor extrañeza provoca que la Sala entendiera como "efectivamente documentada" una "propuesta» (?) así, la que fue "entregada con antelación a los vocales». Lapsus nada neutro, apúntese de paso.

3. El colmo estaba por llegar. A partir de él ya no será posible imputar a la Sala errores excusables (o tropiezos impensables, incluso), porque ahora estamos ante una inequívoca muestra de vistosa manipulación(7), pienso yo.

Y me someteré al mejor criterio de quien esto lea tras copiar el párrafo concernido (con énfasis míos), que dice: «El artículo 45 de dicho Reglamento, en contra de lo que parece defenderse en la demanda, solo prohíbe que se debata en el Pleno sobre temas o materias no incluidos en el orden del día, o carentes de propuesta escrita, pero no puede interpretarse con una rigidez tal que impida completar, mejorar o alterar aquellos particulares de la propuesta en los términos que puedan resultar del debate» (FD 13..$^{\circ}$.

Imposibles de pasar por alto son tres aparatosas tergiversaciones que sobresalen ya nada más mirar. Primero, la Sala equivocaría la denuncia de las recurrentes: éstas no protestan por lo que el Presidente pudo decir de más (siquiera tarde) sino por lo que hizo de menos (al omitir esa información básica cuando debió darla). Segundo, tampoco es verdad la ac-

(7) Preveo que con el uso de esa palabra, por desconsiderada, me ganaré algún toque de atención. En lo que pueda valer como descargo, diré que yo no sería el primero en recurrir a un término tan descalificador hacia una instancia judicial en el ámbito de una publicación académica. Pienso, por ejemplo, en R. GATTONI, "Il manipolatore togato. Appunti sulla condanna di Adriano Sofri», Dei delitti e delle pene, 2000, núms. 1-2. 
ción que la Sala atribuiría al Presidente: por la aplastante razón de que es imposible "completar, mejorar o alterar aquellos particulares de (una) propuesta" todavía no formulada. Tercero, la distorsión alcanzaría proporción aún mayor si esas supuestas operaciones (completar, mejorar, alterar) se presentan como "resultado del debate», siendo así que el documento aportado al Pleno por el Presidente se leyó justo antes de que los vocales comenzaran a debatirlo, para al final quedar tal cual (sin completar, mejorar o alterar) (8).

4. Muy contrariada parece estar la Sala por el recurso pues, por si no le bastara ya con lo hecho y dicho, aún prolonga su arremetida contra las demandantes mediante un argumento ad hominem(9) verbalizado en estos términos: "Según se desprende del expediente y de las propias manifestaciones de la parte actora, ninguno de los vocales planteó la insuficiencia de la propuesta por no contener el nombre de los miembros que habían de designarse, ni adujo su falta de documentación por aquella omisión, ni la contravención de aquellos preceptos del Reglamento como consecuencia de la incompleta propuesta que había formulado el Presidente del Consejo".

Pues bien, al margen del escaso valor del argumento (pues sólo aprovecharía a efectos retóricos (10), y aún así... (11)), la Sala pasa por alto que en el voto particular firmado también por las recurrentes(12) contra el acuerdo del Pleno (anterior, por tanto, al contencioso), la primera de sus "consideraciones» recogía precisamente la denuncia por infracción del art. 45 ROF (lo mismo que la tercera «consideración» y el punto 1 de la "conclusión»). No estamos, por tanto, ante una ocurrencia sobrevenida en el momento de redactar el recurso y cogida por los pelos, si es eso lo que insinúa la Sala. Convendría dejarlo claro.

(8) Es cierto que en el acta de la sesión se alude a unos "flecos», pero en nada afectan al texto del documento que el Presidente aportó al Pleno.

(9) Que tiene todas las trazas del proverbio latino "qui tacet consentire videtur», o del español "quien calla, otorga».

(10) Cambiaría la situación si las demandantes hubieran votado a favor de la famosa "propuesta». No fue el caso.

(11) El acta escrita de la sesión plenaria pone de manifiesto que el rechazo de siete vocales contra la propuesta del Presidente versó sobre aspectos más gruesos que el ahora comentado. Lo cual no autoriza a inferir que, por tanto, éste no suscitaba reparo alguno entre los vocales de la minoría. Y menos, si al expediente se incorporó nada más que el acta escrita (a cuya aprobación, incluso, se opusieron las recurrentes) pero no así la grabación de la sesión plenaria, inclusión solicitada por éstas pero desatendida (por la inexplicable circunstancia de que el soporte de la filmación había sido destruido). ¿Lo sabía la Sala?

(12) Lo mismo que el voto particular firmado en solitario por el vocal don Enrique Lucas. 


\section{II.3. Logicismo irrefrenable}

Sin contemplaciones, igualmente, se fustiga en la sentencia la pretensión de nulidad perseguida por las demandantes al amparo del art. 18.5 ROF, según el cual los vocales del CGPJ tendrían derecho "a formular propuestas escritas y a su inclusión en el orden del día de las reuniones del Consejo"; derecho que se habría conculcado - estiman aquéllas - al no dar cabida en el orden del día tanto a la propuesta de seis vocales como a las tres candidaturas.

1. Si bien - según se dictamina en la resolución judicial- «los defectos formales (...) imputables (...) a la actuación del Presidente (...) han quedado fuera del objeto del proceso como consecuencia del auto de la Sección Primera» (FD 13..$^{\circ}$, eso no obstará a que la Sala acepte el envite dialéctico de mostrar cómo aquellas irregularidades formales («presuntas" nada más, se puntualiza) no comportan el efecto invalidante que las recurrentes pretenden.

Polémica que genera la Sala, sin duda no por el ocioso entretenimiento de exhibir su habilidad para la polémica, sino - me imagino- por evitarle al Presidente el desdoro de un Acuerdo patrocinado por él del que - podría pensarse - había sobrevivido no por méritos intrínsecos suyos sino por superficiales deméritos (una menudencia de plazos) del recurso que lo cuestionaba. En efecto, dejar flotando en el aire esa impresión iría en detrimento de la imagen del Presidente.Y eso sí que no.

2. Ahora bien, dado que el discurso de la Sala se acomoda al diseño de una lógica muy peculiar, debo explicar el porqué de la metafórica denominación "logicismo irrefrenable».

Entenderé por "logicismo irrefrenable» aquél que permite atribuir al hablante (o actor) no sólo lo que éste dice (o hace) sino también lo que el oyente (o espectador) deduce de lo que aquél ha dicho (o ha hecho). O sin tanto circunloquio: si alguien vota a favor de una propuesta, ha de suponerse que también está votando en contra de cuantas opciones conocidas se han barajado en sentido más o menos opuesto, aunque no haya sido preguntado sobre ellas.

Espléndida es la ilustración que al respecto nos brinda la Sala cuando sostiene que: a la vista de que utodos los vocales conocían con la debida antelación tanto la propuesta que formularon aquellos seis, como la disposición de tres consejeros para formar parte de la Comisión Permanente», entonces «el supuesto defecto formal no ha privado a la resolución recurrida de los requisitos esenciales para alcanzar su fin, ni ha producido indefensión material a los destinatarios (...) porque no puede aducir indefensión real y efectiva quien ha visto que sus propuestas - no obstante su 
falta de incorporación formal al orden del día como punto independientehan sido conocidas por los integrantes del Pleno y han podido ser debatidas en su seno en los términos que se deducen del expediente administrativo y de las manifestaciones de la propia parte actora» (FD 13.\%).

Idea que la Sala no ha dejado caer por un casual, sino cuyos destellos se esparcen con insistencia a lo largo de todo el FD $13 .^{\circ}$. Por ejemplo, allí donde la Sala reitera que: "Como se sigue del expediente, el punto del orden del día comunicado a todos los miembros del Consejo con fecha 23 de enero de 2015 contaba con unos Anexos en los que se incluía la propuesta de aquellos seis vocales, así como los escritos presentados por las Sras. Mari Jose, Socorro y Estrella (...) lo que pone de manifiesto que todos los vocales conocían con la debida antelación tanto la propuesta que formularon aquellos seis, como la disposición de tres consejeros para formar parte de la Comisión Permanente. Y del acta de la sesión se desprende también (...) que los vocales del CGPJ debatieron sobre aquella propuesta y pusieron de manifiesto cuanto tuvieron por conveniente sobre cómo había de efectuarse la renovación de las Comisiones". O cuando la Sala remacha que: "tales extremos - no obstante la falta de incorporación formal al orden del día de aquella propuesta- no sólo pudieron ser debatidos (...) con los datos que fueron suministrados al comunicar a los vocales el orden del día de dicha sesión, sino que fueron efectivamente objeto de votación y debate». O, en fin, hasta votaron los consejeros contra la pretensión de doña Mari Jose de renunciar a su vocalía en la Comisión Disciplinaria en caso de ser elegida para la Permanente, pues en la propuesta del Presidente que el Pleno votó «se excluía a los miembros de la Comisión Disciplinaria».

3. Tal es el ardor que se pone en la sentencia para destacar la cantidad de asuntos sobre los que (presuntamente) se pronunció el Pleno, que podría quedar en la penumbra un hecho que también se consigna en la resolución y debe resaltarse por si pasa desapercibido: que el Pleno "decidió votar única y exclusivamente una propuesta, la del Presidente del órgano" "una vez concretados los nombres de quienes habían de integrar las referidas comisiones». Eso sí: "tras las diferentes intervenciones en el debate».

De donde, y de conformidad con este razonamiento, procedería entonces diferenciar dos partes en el objeto de la votación: una parte explícita (la composición de las distintas comisiones con los nombres de sus respectivos vocales) y otra parte implícita (el resto de lo debatido). De suerte que el voto explícito en un sentido acarrea automáticamente un voto implícito en sentido coherente con el primero; y, por tanto, el voto explícito hace superfluo votar sobre lo que implícitamente ya se derivaría de aquél. Así de expeditivo. Pero con grandes agujeros. 
4. El fundamental, que el contenido de una propuesta sometida a votación no está constituido por una red de implicaciones lógicas impersonales (es decir, independientes de lo que piensan que votan y quieren votar las personas concernidas) ni libres de servidumbres contextuales (o sea, del dónde y cuándo).

A) De entrada, no a todas las personas les funciona lo mismo la lógica ni a todas la misma lógica. Por ello, ante todo han de convenir los votantes en cuáles son los términos precisos de lo que van a votar. $Y$ si, por ventura, alguien pretende que el objeto de la votación así delimitado incluye algunos implícitos, éstos han de quedar convenientemente explicitados (dejando ipso facto de ser implícitos).

De otro lado, la voluntad es consustancial al acto de votar. Voluntad que abarca dos facetas: no sólo la de optar por el sentido del voto sino igualmente la de acotar el objeto de la votación. Se vota sólo sobre lo que se quiere votar y no a pesar de lo que se quiera votar (por fuertes que fueren los imperativos racionales a favor de incluir lo que, sin embargo, deliberadamente se ha excluido de la votación - no importa por qué motivos-).

A no perder de vista, tampoco, la dimensión institucional de la votación, con sus inevitables reglas de juego que, entre otras funciones suyas, determinan cómo se fija y delimita el contenido de lo que se vaya - primero - a debatir y - después - a votar.

B) Sentadas las premisas, es momento de extraer las consecuencias aplicables a la situación.

a) Empezando por el final, no todo intercambio dialéctico que se produce entre vocales durante el transcurso de un Pleno vale como debate preliminar de una votación. Lo sabe la Sala y así nos lo enseña ella misma en un fragmento de la sentencia que reproduje más arriba; aquél que decía: «El art. 45 de dicho Reglamento (ROF) (...) solo prohíbe que se debata en el Pleno sobre temas o materias no incluidas en el orden del día, o carentes de propuesta escrita" (FD 13. ${ }^{\circ}$ ). Entiendo, por tanto, que la inclusión en el orden del día es, si no condición suficiente, al menos sí condición necesaria.

Así las cosas, en el orden del día del polémico Pleno, y a excepción del dichoso apartado cuarto, no figuraba ninguna de las otras materias o propuestas sobre las cuales, no obstante, la Sala alega (contra las recurrentes) que fueron debatidas y votadas. Entonces, si en el Pleno no se observaron las prescripciones reglamentarias del art.45, la Sala nos debe alguna explicación para disipar su aparente incoherencia.

A menos de que la Sala se haya guardado un as en la manga: quizás aquél que dejó entrever cuando replicaba que el orden del día entregado 
a todos los vocales "contaba con unos Anexos en los que se incluía la propuesta de aquellos seis vocales, así como los escritos presentados por las Sras. Mari Jose, Socorro y Estrella» (FD 13. ${ }^{\circ}$ ). Si así fuera, el hecho de que tales asuntos no aparecieran inscritos en el listado del orden del día, y se contraviniera lo dispuesto por el art.45 ROF, tendría para la Sala la nimia enjundia de un "supuesto defecto formal" o de una "falta de incorporación formal como punto independiente» (FD 13. ${ }^{\circ}$ ) nada más. Habría de colegirse, en consecuencia, que - para la Sala - aquellos asuntos formalmente omitidos constituían materialmente parte del orden del día y - debe suponerse entonces - que conferían a sus proponentes el derecho a exigir que fueran debatidos y votados con las garantías de rigor. Pues bien, resulta que ni el Presidente ni los propios vocales que lo secundaron lo entendían así. ¡Curioso!

b) Basta repasar el acta de la sesión plenaria para cerciorarse de ello. Frente a las protestas, por ejemplo, de la vocal Martínez de Careaga (que «muestra su sorpresa porque se esté debatiendo únicamente (...) la propuesta del Presidente y no la propuesta formalizada por el grupo minoritario") o de la vocal Cinto Lapuente (la cual "entiende que hay vocales que han presentado su candidatura a ser miembros de la Comisión Permanente y tendrían derecho a que dichas candidaturas sean debatidas en el Pleno»), el acta deja constancia de que "el Presidente interviene brevemente para aclarar que el punto del orden del día que se debate es la propuesta del Presidente (...) que se ha formalizado al comienzo de este Pleno", lo que aprovecha el vocal Grande-Marlaska para sugerir - en esta misma onda - que se tenga por finalizada la discusión pues «considera que se ha debatido suficientemente la propuesta y que los nombres de los integrantes de las comisiones están encima de la mesa».

Constatado lo cual, nada extraña que las demandantes pregonaran con áspero acento, en el voto particular que suscribieron, su denuncia porque uen la sesión del Pleno de 29 de enero (...) se denegó la posibilidad de someter a votación la propuesta formulada por los seis vocales peticionarios", vulnerándose "la facultad inherente de someter propuesta al Pleno para su decisión, y la consiguiente exigencia de su votación y concreción de la voluntad colegiada». Reproche que, de manera similar, también se agita en el voto particular del vocal Enrique Lucas («Existía una propuesta de sistema de votación presentado formalmente con anterioridad a la convocatoria de la sesión plenaria por seis miembros del Pleno y pese a que se habían postulado como candidatas tres vocales, el presidente rechazó debatir sobre ello»).

c) No se trataba pues de la mera "falta de incorporación formal como punto independiente» de unas propuestas, como si aquélla hubiera sido 
fruto de un descuido. No. Es más, ya la reiterada resistencia del Presidente (primero en diciembre de 2014 y después en enero de 2015) a introducir en el orden del día ambos asuntos denota un deliberado propósito no se sabe con qué fin, pero desde luego no reductible a una formalidad venial.

Tiene su gracia (mucha pero maldita) que la Sala venga proclamando que se votó (siquiera implícitamente) lo que (explícitamente) se vetó (votar).

\section{II.4. Escamoteo sistemático}

En las postrimerías de la sentencia (FD 14. ${ }^{\circ}$ ), el Tribunal elude la última pretensión de las demandantes, a saber: que se determine el sentido del art. 601 LOPJ, porque de su aplicación penden también derechos inherentes al ius in officium. La Sala no se muestra por la labor.

1. Ésta se entretiene, de inicio, en unas salvas de fusilería que no apuntan al corazón del problema. Así, a la Sala le parece en «extremo relevante» que este "tercer motivo de nulidad se articule de manera subsidiaria», e igualmente le "resulta ilustrativa la forma en que se fundamenta» porque - continúa - «no encontramos ni una sola vinculación entre el repetido ius in officium y la decisión material del Pleno de fijar la composición de la Comisión Permanente incluyendo a unos u otros vocales en los términos acordados por la mayoría»; lo que denota que "ni siquiera las recurrentes se han esforzado mínimamente en constatar que una interpretación distinta de la adoptada por el Pleno de las expresiones "elegirá anualmente" o "se procurará la rotación anual" (empleadas por el art. 601 LOPJ) era la única que respetaría en su integridad el adecuado ejercicio de las funciones esenciales que la ley les atribuye como vocales» (FD 11. ${ }^{\circ}$.

A) Respecto de lo uno, lástima que la Sala no reproduzca los petita de la demanda para advertir que la "subsidiariedad" del motivo - que de ningún modo prejuzga que éste fuera de relleno- carece de toda relevancia. Pues es normal que primero se juegue la baza más radical de la nulidad del acuerdo impugnado (por haberse prescindido «total y absolutamente del procedimiento legalmente establecido") y, "subsidiariamente», la de su anulación (por «infracción del art. 601.2 de la LOPJ»). Tal fue el caso(13).

(13) Lo corrobora otro fragmento de la demanda donde se lee: "Con independencia de mantener que el acuerdo adoptado por el Pleno del CGPJ (...) es nulo, la pretendida renovación no fue realmente tal (...). Lo que vulnera en relación a la Comisión Permanente lo dispuesto en el art. 601 LOPJ" (pp. 30-31). 
B) Por otra parte, inequívoca y expresa (pp. 27-28 de la demanda) es la conexión que establecen las demandantes entre el ius in officium y lo dispuesto en el mencionado artículo de la LOPJ. ¿Con qué fundamento? Con el de la apabullante literalidad del precepto y su aderezo explicativo que se ofrece en la Exposición de Motivos. Si, en opinión de aquéllas, la claridad textual de ambos elementos no tiene vuelta de hoja y si, de otro lado, la mayoría no expresó en el Pleno razones(14) (no votos) para sostener una interpretación alternativa ¿en qué tipo de razonamiento deberían haberse empeñado las recurrentes? Y si hubiera una exégesis plausible y distinta a la preconizada por éstas ¿por qué no la pone de manifiesto la Sala antes de recriminar a las demandantes su indolencia por «ni siquiera (haberse) esforzado mínimamente» en demostrar que su interpretación era la única correcta? ¿Había otra acaso? ¿Cuál?

2. No cabía esperar de la Sala respuesta alguna, a la vista de que ella no se ha ocupado de una tarea aún más básica y preliminar: reproducir de cuerpo entero (no bastan fragmentos sueltos y rebotados) los datos normativos concernidos para, así, poder hablar sobre seguro.

A fin de paliar esa deficiencia no sería ocioso remitirse al apartado IV de la Exposición de Motivos, donde se lee que: "para permitir una mayor pluralidad en la composición de la Comisión Permanente se prevé su renovación anual, estableciendo de este modo la posibilidad de que todos los vocales, con excepción de los que integren la Comisión Disciplinaria, puedan llegar a formar parte de la misma».

Una vez identificada la teleología del art. 601.2 convendría retornar a la textualidad del mismo por ver si se atisban márgenes interpretativos en su lectura. El citado precepto, tras establecer la composición de la Comisión Permanente, puntualiza: "Con excepción de los miembros de la Comisión Disciplinaria, se procurará la rotación anual del resto de los Vocales en la composición anual de la Comisión Permanente».

Trabajo baldío, sin embargo. Porque, llegados a este punto y con elementos suficientes para al menos descartar de plano que el Acuerdo adoptado por el Pleno fuera compatible con lo legalmente dispuesto, caemos en la cuenta de que la Sala va a desentenderse de la discusión que ella misma había suscitado (de nuevo bajo la forma de un argumento «ad hominem») negándole ahora toda incidencia en el objeto del recurso. Dirá que:»las demandantes pueden legítimamente defender la forma en

(14) Lo único que consta en el acta del Pleno es: por un lado, la injustificada interpretación del Presidente acerca de que la ley no determina si la rotación ha de ser "total» o puede ser "parcial»; y, por otro, la opinión del vocal Martínez Moya para quien «el mandato de la norma no es de carácter imperativo" (no aclara cuál es su naturaleza) "y que en consecuencia la interpretación de la misma puede ser diferente» (sin precisar qué interpretaciones serán las viables ni por qué). 
que ha de producirse la renovación anual de la Comisión Permanente; pueden sostener en qué términos debe efectuarse la rotación de los vocales $(\ldots)$ y pueden también, obvio es decirlo, discrepar de la interpretación que sobre esos extremos ha sostenido un número de vocales mayoritario", pero "la defensa de una interpretación distinta (...) solo puede hacerse en el seno del órgano colegiado al que pertenecen" por tratarse de una "pretensión de legalidad desconectada del interés legítimo", aquél que - de haberlo - sí permitiría «impugnar ante esta Sala la decisión del Pleno». ¿Demasiado simple? Puede.

3. En su aproximación al art. 601 la Sala deslinda dos asuntos distintos: uno se refiere a cómo se regula en la ley la rotación anual de los vocales; el otro atañe a si esa norma legal implica o no un ius in officium de los vocales. El primero se sustancia en una cuestión de mera "legalidad" $y$, en cuanto tal, ha de resolverse sin traspasar los umbrales del Pleno; el segundo genera una cuestión de "interés legítimo" de los vocales, cuya tutela sí corresponde en última instancia a los tribunales.

A) Son, sin duda, cuestiones diferentes, pero ¿también independientes? Veamos. Si el «interés legítimo» existe en tanto que -como dice la Sala - una «norma jurídica reconoce a los miembros del Consejo un derecho a formar parte de alguna de las comisiones o de hacerlo en un momento temporal o en otro"(FD 14..$^{\circ}$ ), entonces no sería baladí explorar si, de la rotación de todos los vocales prescrita en el art.601, «surge para los/ las vocales algo más que una mera expectativa en relación con la posibilidad de, a lo largo del mandato del CGPJ, ejercer en plenitud las funciones que constitucionalmente vienen encomendadas al órgano" (15). Es decir, a expensas de la interpretación del mencionado artículo quedará determinar si el significado de la "rotación" se reduce a una mera cuestión de legalidad o si afecta también a las facultades que los vocales del Consejo pueden desarrollar a lo largo de su mandato.

O lo que viene a ser lo mismo: la interpretación del art. 601 viene a ser un prius (para fijar su alcance normativo) y no un posterius (confiado al Consejo, merced a la gratuita suposición de que solo afecta a pretensiones de mera legalidad). No ha lugar, por tanto, a que la Sala muestre su extrañeza (o presuma de perspicacia) al destacar que (en la demanda) «en el fondo, se está interesando de la Sala que emita una declaración sobre cuál deba ser la interpretación del artículo 601 LOPJ" (FD 14. ${ }^{\circ}$. ¡Pues claro!

(15) Como oportunamente se inquiere en el voto particular (a esta sentencia) redactado por el Magistrado Sieira Míguez y respaldado por otros cuatro Magistrados. 
B) El procedimiento a seguir en el abordaje del problema es de manual. Primero, interpretar ese art. 601 (con la finalidad de establecer si la "rotación" prevista implica o no algún derecho de los vocales a formar parte de la Comisión) y justificar el resultado interpretativo obtenido. Después, si el resultado ha sido afirmativo, delimitar (por vía interpretativa), también argumentadamente, el perfil y el alcance del derecho identificado. Por último, controlar si la renovación de la Comisión efectuada es compatible o no con el derecho previamente acotado, razonando la valoración resultante.

C) Obviamente el itinerario procedimental se simplifica si el primero de los tres pasos se salda ya con una respuesta negativa, pues ahí terminaría todo. Es lo que parece haber sucedido en esta ocasión.

Ocurre, sin embargo, que poco o ningún esfuerzo interpretativo ha realizado la Sala para llegar al susodicho resultado. Hasta diríase que, formalmente al menos, la Sala ha esquivado afrontar esa tarea, dando la impresión de que nos ofrece más una premisa apriórica que una conclusión fundamentada.

Véase si no con qué palabras despacha la cuestionada conexión entre el ius in officium y la "rotación" prescrita por la LOPJ: "No creemos que el derecho al cargo ( $y$ el ejercicio sin restricciones de las facultades que tal cargo confiere a su titular) resulte afectado o lesionado por el hecho de que el Pleno no acepte una determinada forma de proceder en relación con el procedimiento para conformar las distintas comisiones". ¿Y eso por qué? "Sobre todo (porque) ninguna norma jurídica reconoce a los miembros del Consejo un derecho a formar parte de alguna de esas comisiones o de hacerlo en un momento temporal o en otro" (FD 14. ${ }^{\circ}$ ). ¿Tampoco el art. 601 LOPJ? "Partiendo del hecho no controvertido de que no existe en la normativa vigente un derecho de los vocales a formar parte de una u otra Comisión del CGPJ, o a hacerlo en un determinado momento, o durante un concreto plazo, no alcanza la Sala a entender en qué medida una decisión mayoritaria del órgano competente sobre el alcance y significación de aquellas expresiones contenidas en el artículo 601 puede afectar al ius in officium de los vocales que han discrepado del acuerdo mayoritario" (FD 11. ${ }^{\circ}$ ).

Dejando de lado que no se ajusta a la realidad adjetivar como «no controvertido" un "hecho" tan omnicomprensivo ("la normativa vigente", que abarcaría por tanto al propio art. 601)como el mencionado por la Sala (pues, sin ir más lejos, las demandantes lo discuten), no cabe amordazar el dato de encontrarnos aquí ante una situación inédita (surgida por primera vez) que obliga a preguntarnos si lo que la Sala predica in genere de "la normativa vigente" (no se sabe con qué razón) es aplicable o no y por qué al art. 601. Para eso haría falta interpretarlo, claro está. Estaría bien saber por qué la Sala se resista a hacerlo. 
En lugar de ello, la Sala sigue rayando el disco de que el art.601 no da para más que para plantear "una pretensión de mera legalidad". ¿Alguna razón? Ninguna. Sólo la escueta y autocrática remisión a lo que «hemos señalado reiteradamente» (FD $14 .^{\circ}$ ), sin otra explicación.

Trabajo recibido el 4 de abril de 2017

Aceptado por el Consejo de Redacción el 26 de mayo de 2017 
LABURPENA: Garrantzitsua da modu onek gida dezatela gure erakundeen funtzionamendua, alde batetik jarduera ilunak eta, bestetik, tratu bereiziak saihestuz. Iruzkingilearen iritziz, bi betekizun horiek ez dira behar bezala errespetatu ez Auzitegiko epaiketan amaitu zuen benetako historian, ez historia horretaz arduratu zen epaiketaren epaian. Kritikagarriak dira bai jokaera batzuk (Botere Judizialaren Kontseilu Nagusiaren barruan gertatutakoak), bai arrazoiketa ugaritan edukitako antzeko jarrera (3. salarena). Hori guzti hori, Kontseiluko Batzorde Iraunkorra berritzeko akordioaren harira eta Administrazioarekiko Auzien Salaren aurrean inpugnatu ostean.

GAKO HITZAK: Botere Judizialaren Kontseilu Nagusiaren batzordeak. Berritzea. Errotazioa. Ius in officium. Interpretaziozko arrazonamendua.

RESUMEN: Importa que las buenas maneras presidan el funcionamiento de nuestras instituciones evitando - por un lado- las oscuras actuaciones y los desiguales tratos - por el otro-. En opinión del comentarista, ambos requisitos no han sido convenientemente respetados ni en la historia real que desembocó en el juicio ante el Tribunal ni en la sentencia de éste que se ocupó de aquélla. Criticables algunos comportamientos (en el seno del CGPJ) y actitud nada equidistante (de la Sala $3^{\mathrm{a}}$ ) en no pocos de sus razonamientos. Todo ello con ocasión del Acuerdo para renovar la Comisión Permanente del Consejo y de su posterior impugnación ante la Sala de lo Contencioso-Administrativo.

PALABRAS CLAVE: Comisiones del CGPJ. Renovación. Rotación. lus in officium. Razonamiento interpretativo.

ABSTRACT: Good manners matter when presiding over the functioning of our institutions by avoiding - on one side- shady dealings and unequal treatments -on the other-. In the opinion of the commentator, both requirements have not been duly respected nor in the real story that led in the trial before the Court nor in the ruling by this latter when dealing with the former. Objectionable as they were some behaviors (within the General Council of the Judiciary) and with a non equidistant attitude (by the Third chamber) in many of its reasonings. All of it at the time of the Agreement to renew the Permanent committee of the Council and its posterior challenge before the Contentious-Administrative chamber.

KEYWORDS: Committees of the General Council of the Judiciary. Renewal. Turnover. lus in officium. Interpretative reasoning. 